\title{
EDITORIAL
}

\section{Educación Parvularia, Educación Pública y Revista IEYA: nuestro comienzo}

Hace algún tiempo le escuchamos a Francisco Gutiérrez, educador español radicado en Costa Rica, y antiguo colaborador del educador brasileño Paulo Freire, comentar que la metodología freiriana había fracasado. Al decir estas palabras, algunas de las personas que en aquel momento lo escuchaban mostraron su indignación ante tal comentario, pero Francisco Gutiérrez aclaró: "la metodología freiriana ha fracasado porque le quitaron lo verdaderamente relevante, a Paulo Freire”.

Tremenda reflexión ésta en los momentos en los que nos encontramos, en donde se habla de educación y se toman decisiones al respecto haciendo desaparecer y sin tener en cuenta a los verdaderos protagonistas de dicho proceso: los educandos y las educadoras/es. Reforma tras reforma, curso tras curso, capacitación tras capacitación. Todo cambia pero pareciera que todo siga igual. ¿Cuál es el valor de una política determinada cuando ésta se ha construido a espaldas de los profesionales del área en cuestión? ¿Creemos que esas políticas pueden, verdaderamente, generar cambios profundos en la forma de ser, sentir, pensar y actuar de las educadoras y los infantes? ¿Podemos educar para la construcción de una sociedad más justa cuando muchas de las autoridades políticas y educativas que construyen las políticas poseen, en lo más profundo de su ser, tremendas convicciones segregadoras?

Si entendemos la educación como el proceso de creación de relaciones posibles, como diría Calvo (2012), necesitamos entender que la participación de las educadoras y de los niños/as en la construcción de las políticas públicas para la educación de la infancia no es algo aconsejable, sino un requisito para el éxito de las mismas. Sentirse parte de un proceso, tener la libertad y la autonomía para decidir, para tomar decisiones, etc., es estar educándose constantemente, como lo hacemos en nuestra vida cotidiana del día a día; características éstas que pareciera que tenemos que abandonar cuando entramos en el espacio formal - institucionalizado de las instituciones políticas y educativas, pues éstas parecieran querer enseñar a participar, a ser autónomos, democráticos, críticos, etc., sin que 
ninguna de estas características estén presentes en dichas instituciones, ni para el alumnado ni para las educadoras, y menos aún para la organización de la institución.

Es desde esta situación y a pesar de los problemas descritos, que la carrera de Educación Parvularia de la Facultad de Medicina de la Universidad de Valparaíso, Chile, se ha comprometido con un sueño, una utopía. El sueño y la utopía de entregarle a la V Región de Chile y al país una instancia de reflexión, análisis y diálogo que pueda constituirse en un referente para la mejora de la Educación Parvularia que Chile necesita. Una mejora que nazca desde las propias profesionales del área y de otros profesionales comprometidos con la Educación Infantil.

"La utopía está en el horizonte. Camino dos pasos, ella se aleja dos pasos y el horizonte se corre diez pasos más allá. ¿Entonces para que sirve la utopía? Para eso, sirve para caminar"

(Eduardo Galeano)

La Revista "Infancia, Educación y Aprendizaje" (Revista IEYA) pretende ser un instrumento que nos permita caminar hacia una educación parvularia de mayor calidad en el sentido de lo público.

Una Educación Parvularia, en el sentido de lo público, capaz de generar formas de vida en comunidad en donde sus miembros tengan, construyan y sueñen con intereses compartidos, aspecto éste incentivado por una verdadera formación democrática. Formación democrática centrada y focalizada en la solidaridad y la colaboración como ejes centrales del proceder político y pedagógico y en donde la libertad y la autonomía se convierten en los principios políticos y éticos que guían el proceder de las instituciones educativas relacionadas con la infancia.

En un ambiente como el descrito, el conflicto ya no es algo a castigar ni a disuadir, sino que es relevado como positivo y constructivo, pues el énfasis de una Educación Parvularia Pública está centrado en una formación en una ética del disenso y el desarrollo de la capacidad crítica y reflexiva que invite a trabajar en la construcción de un mundo más justo, más equitativo, tanto al interior de la comunidad educativa como en los espacios circundantes, cercanos y/o lejanos, a ella. 
Es desde aquí que el Vol. 1, No. 1, de la Revista IEYA, ha sido capaz de recoger las voces de destacadas educadoras de párvulos, psicólogos, antropólogos, filósofos, profesores de educación física, educadoras diferenciales y médicos, tanto chilenos como extranjeros. Voces que tensionan el concepto de infancia, el aprendizaje y la educación para poder contribuir al debate nacional actual sobre la educación en los primeros seis años de vida.

Corporeidad y cuerpos, gestos, propensión a aprender, mediación pedagógica, el cuidado, la lactancia materna, derechos de la infancia, el juego, el tiempo, el aprendizaje servicio solidario y la evaluación son las problemáticas abordadas en este primer número de la Revista IEYA que ahora presentamos.

Además de la diversidad de problemáticas y áreas del conocimiento a la que pertenecen los autores/as, la Revista IEYA cumple con otros dos criterios que para nosotros son relevantes en la producción científica y técnica de cualquier área del conocimiento. Por un lado encontraremos diversidad de relatos, formas diferentes de comunicar la ciencia. Ello porque queremos y estamos convencidos de que dicha diversidad narrativa permitirá llegar a un público diverso: educadoras, investigadoras, académicas, padres y madres, etc. Por otro lado se podrá apreciar cómo la diversidad geográfica está presente, dada la diferente procedencia geográfica de los autores/as: desde Chile (La Serena, Talca, Valparaíso, Santiago y Valdivia), hemos podido comunicarnos con Brasil y España. Y desde aquí tenemos la convicción de que en los próximos números contaremos con la presencia de otros países cercanos y lejanos.

Estamos convencidos que IEYA cubrirá un espacio técnico, científico y académico sobre la educación parvularia que el país necesita.

\section{Referencias bibliográficas}

Calvo, C. (2012). Del mapa escolar al territorio educativo: disoñando la escuela desde la educación. Santiago de Chile: Editorial Nueva Mirada.

María I. Bustos Venegas

Directora Revista IEYA

E-mail: mary.bustos@uv.cl
Alberto Moreno Doña Editor Jefe Revista IEYA

E-mail: revista.ieya@uv.cl

8 de septiembre 2015 